\title{
What information do people with cirrhosis and their family members want during out-patient appointments? A qualitative study exploring the perspectives of patients, close family member and liver health professionals.
}

Joseph T S Low ( $\square$ joseph.low@ucl.ac.uk)

University College London https://orcid.org/0000-0003-1499-5216

\section{Sarah Davis}

University College London

Jo Wilson

Royal Free London NHS Foundation Trust

Lynda Greenslade

Royal Free London NHS Foundation Trust

Jennifer-Louise Clancy

Royal Free London NHS Foundation Trust

Cathy Carroll

Royal Free London NHS Foundation Trust

Rachel Craig

Royal Free London NHS Foundation Trust

Aileen Marshall

Royal Free London NHS Foundation Trust

Douglas Thorburn

Royal Free London NHS Foundation Trust

Patrick Stone

University College london

Research article

Keywords: cirrhosis, palliative care, supportive care, communication

Posted Date: December 4th, 2019

DOl: https://doi.org/10.21203/rs.2.18038/v1 
License: (c) (i) This work is licensed under a Creative Commons Attribution 4.0 International License. Read Full License 


\section{Abstract}

Background: Good communication between health professionals and patients is important in healthcare, but difficult to implement in practice. This is highlighted in care for people with cirrhosis where patients have little understanding about their disease and feel stigmatized when communicating with health professionals. No study has explored the conversation exchanges between health professionals and patients with cirrhosis. This paper reports on secondary data analysis to explore the contents of patient doctor communication in hepatology out-patient clinics.

Methods: Semi-structured interviews and focus groups were conducted with 12 patients, 5 close family members and 14 liver health professionals, aimed at exploring aspects of the consultation: questions asked or not asked during the consultation, the ease of answering questions, understanding of information received, and their preparation for the consultation. All interviews were audio-taped and data analysed using framework analysis.

Results: Questions discussed centred on test results, symptoms and their management. Patients and family members felt comfortable with asking health professionals questions, but wanted better information about prognosis, the effects of medication on their symptoms and the likelihood of further deterioration in their liver disease. Patients had difficulty in understanding information received as it was couched in technical terms. Emphasis in consultations focused on the physical aspect of patient care leaving little time to discuss the psychological impact of their disease. Some clinicians felt patients should ask questions about their future, particularly about advance care plans. Key barriers in asking questions included: a) limited time for out-patient appointments, b) expectation that only medical issues could be discussed, c) fear about giving 'negative' information to patients, d) memory issues resulting from hepatic encephalopathy.

Conclusions: Health professionals should use simple language when providing patients and their families with explanations about liver disease, its physical and psychological impact and prognosis. Information sheets about these topics should be made available for patients to take home. Doctors should be willing to explore supportive care issues with patients or consider referring patients to another health care professional with more time and expertise to discuss specific issues. Further work needed to explore the interactions between these groups using observational methods.

\section{Declarations}

Ethics approval and consent to participate: Ethical approval obtained from the Yorkshire \& The HumberSheffield Research Ethics Committee (17/YH/0042).

Competing interests: The authors of this paper have nothing to disclose.

Consent for publication: Not applicable 
Data availability statement: The datasets generated during and/or analysed during the current study are available from the corresponding author on reasonable request.

Funding: This study received no specific grant from any funding agency in the public, commercial or notfor-profit sectors, but Research Department responsible for conducting this study is provided core funding by Marie Curie (Grant reference: MCCC-FPO-16-U). PS, JTSL and SD's post is supported by the Marie Curie core and programme grant funding (grants MCCC-FCO-16-U and MCCC-FPO-16-U). The funder played no role in the collection, analysis and interpretation of data, in the writing of the report; and in the decision to submit the article for publication.

Authors contributions: JL, SD, LG, RC, JW, AM, DT and PS were responsible for the study concept and design; JL, SD, LG, J-LC and CC were responsible to the acquisition of the data; JL, SD, LG, CC, RC, JW, JLC, AM, DT and PS were responsible for analysis or interpretation of the data; JL, drafted the initial manuscript; SD, PS, LG, CC, RC, JW, J-LC, AM and DT revised the manuscript critically for important intellectual content; all authors gave the final approval of the version to be published.

Acknowledgements: We would like to acknowledge Marie Curie for providing funding for the Research Department responsible for conducting this study (Grant reference: MCCC-FPO-16-U). We acknowledge the support of the UCLH BRC (Biomedical Research Centre). Finally, we would like to thank all the participants involved in this stage of the research for their time and support with this study.

\section{Introduction}

Good communication between healthcare professionals and their patients is essential to encourage patients to be active participants in their own healthcare(1). In practice, good communication is often difficult to implement. This is highlighted in the case of delivering health care to people with cirrhosis (2), where a limited number of studies have shown inadequate doctor-patient communication(3), in which consultation times are too short for effective information exchange(2) and with too much focus on disease modification $(2,4)$. Patients feel stigmatized when communicating with health professionals(5) because of the association of liver disease with substance misuse(6-9). Patients with alcohol-related liver cirrhosis want to discuss methods of combatting alcohol addiction(10). Patients have little understanding about their disease, its progression or its impact(2), a fact acknowledged by liver health professionals(11). At the same time, liver health professionals often lack the skills or confidence to have conversations about these topics $(2,11)$. From patients' perspectives, their lack of understanding about their own disease limits their ability to ask appropriate questions during their consultations with medical staff(2).

Previous studies were not specifically designed to explore communication issues in patients with liver disease, so the themes that were identified arose from participants' experiences of discussing their disease with health professionals. No studies have explored the actual contents of the questions asked or what was discussed during the consultation. It is important to explore these exchanges to gain a better 
understanding of what health professionals are happy to discuss and why certain topics are not raised(12).

We have recently conducted a study to develop a liver-specific Question Prompt List (QPL) as a communication aide. As part of the development process, we sought to identify questions asked by patients to their liver health professionals(13). We have conducted a secondary analysis of this data to explore, in greater depth, patient doctor communication in hepatology. We have done these by looking at the questions asked during out-patient consultations, the topics health professionals were happy to discuss with their patients and those that patients wanted to discuss.

\section{Method}

\section{Design:}

Qualitative descriptive study using semi-structured interviews and focus groups.

\section{Setting:}

Out-patient clinics in a tertiary liver transplant unit based in Southern England (United Kingdom).

\section{Participants and recruitment:}

We recruited patients diagnosed with cirrhosis, close family members attending clinics with these patients, and health professionals caring for patients with cirrhosis in these clinics. The eligibility criteria for inclusion in the study are shown in Box 1.

Potentially eligible patients and close family members were identified by the clinical team, informed about the study and invited back at a convenient date to enrol in the study after obtaining written informed consent. Patient participants were purposively sampled for: age; gender; different causes of liver disease; extent of disease. Close family members were a convenience sample.

Liver health professionals at the participating centre were contacted, either face to face, by telephone or by e-mail and were enrolled in the study after obtaining written informed consent. Liver health professionals were a mixture of doctors, nurses and allied health staff working in liver out-patient clinics with a range of experiences in hepatology.

\section{Data collection}

Interviews (17 individual and 4 group) were conducted with eligible participants between June and December 2017, lasting between 12 - 31 minutes. Interviews with patients and close family members covered the following topics: 1) the questions which were asked during the consultation; 2 ) uncomfortable questions not asked during the consultation; 3 ) the ease of asking questions; 4) the 
understanding of information received; 5) retention of information and; 6) preparation for the consultation. These topics were similar to those used by McJannett et al (2003)(14) (Box 2).

For health professionals, the interviews/focus groups covered the following areas: 1) topics that health professionals were happy to discuss and questions that they are commonly asked in outpatient consultations; 2 ) other questions that they felt that patients ought to be asking them; 3 ) topics that they felt uncomfortable about addressing (Box 2).

Participants were offered the choice of either a face-to-face or telephone interview. All interviews were audio-recorded.

\section{Data analysis}

Framework analysis(15) was used. Researchers (JL/SD) independently listened to audio-recordings in their entirety to familiarise themselves with the data. The indexing stage was conducted using questions from the interviews as general themes. Key issues arising from each question were transferred to the appropriate section of the framework grid. In all cases, an edited version of participants' responses was used. The data were then rearranged according to their thematic content to allow easy comparison, both within and between participants. Further analysis was conducted to identify links between the different items. To enhance the validity and reliability of the process, the researchers independently conducted theme generation, before meeting to discuss results.

\section{Results}

\section{Participants' demographic details (Table 1)}

Twelve patients (of 22 patients approached) participated, together with five close family members (of eight approached). Patient participants were predominantly male (60\%) with a median age of 51 years (range 31-69 years), and had a variety of liver diseases, the largest group being alcohol-related liver disease $(50 \%)$. Close family members were mainly male and were a mix of parents or sons supporting the patient. Health professional participants were seven doctors, six nurses and one Allied Health Professional.

\section{Preparation for the out-patient appointment}

Of the 12 patients interviewed, seven had attended their appointments by themselves and the remaining five attended with either a family member (spouse or adult child), or with a friend. Those attending with a family member/friend, reported that the presence of this companion was useful as an additional information gatherer, as an aid to information retention, or as an advocate if the patient had memory or cognitive issues.

Of the 11 patients who responded, most had done some preparation for their appointment (10/11) as they had either discussed with their family members the issues they wanted to raise with the health 
professional (5/11) or had specifically prepared a list of questions for the appointment (6/11). Two said that they did not prepare. One explained that it was difficult to prepare until he had spoken with the health professional as he was not aware of his current medical status.

\section{Key findings}

The key findings covered five domains.

\section{Questions asked during out-patient appointments}

Four main questions were discussed during out-patient consultations: test results, symptoms and their management, medication and requests for information about liver disease (Table 2). Patients wanted to know a range of information about their liver disease, ranging from the extent of disease progression and prognosis, treatment availability, advice on how to improve liver function or general health.

Other issues included questions about diet, the availability of psychological support, the impact of the disease on patients and their family members, maintaining the patient at home and practical issues relating to driving, and financial and social support. Patients on the transplant list (and their close family members) also wanted to know about their position on the transplant list, the practicalities of waiting for a transplant and technical questions about donor back-ups and the transplant procedure.

\section{Topics not covered during the outpatient consultation}

Most patients and family members did not feel restricted about asking health professionals questions, but both patients and health professionals felt that certain topics were not covered (Table 2). Some wanted better information about their prognosis, or what would happen if their liver disease deteriorated. Others were unclear about the potential effects of medication on their symptoms. Patients and family members wanted more information about other available treatments or foods they could eat. Some clinicians felt that patients should ask more questions about their future, particularly about advance care plans and the need to write a will. For patients on the transplant waiting list, clinicians felt that patients should ask questions about their expectations about the benefits and burdens of transplantation.

\section{Barriers to asking questions}

Six themes were identified as barriers to asking questions: limited time available during out-patient appointments; expectations about topics to discuss; fears about negative information; memory issues affecting patients as a result of their liver disease; doctors only discussing test results; and the stigma associated with liver disease. The limited time allocated to each out-patient consultation (approximately 15 minutes) was seen by both patients and health professionals as a key barrier to determining which questions were asked. Some were conscious of using up clinicians' time unnecessarily and trusted that 
clinicians would tell them about issues that they were most concerned with, as highlighted by this patient.

"I like to hear the doctor's view on things [her liver disease]. If you ask too many questions, you are not necessarily getting information that you haven't thought about and it takes up too much time (from the consultation)." (3101, female, Idiopathic cirrhosis).

Most clinicians saw the focus of the outpatient appointment as the management of the patient's health condition. The limited time available provided some consultants with a rationale to limit their discussion to medical issues and not to other issues such as the patient's prognosis, which they might find difficult to answer in a 15 minute consultation.

Most of the consultation is about 'what is - I've got ascites, I have aches and pain, I've not been able to eat, rather than battling with the real questions 'where next, where is this all going?' But if they ask this, a consultation of 10-15 minutes becomes 45 minutes. It's having time and resources to deal with it adequately, so you don't encourage the patient to ask, because you have no solution to offer without a multi-disciplinary team." (Doctor - consultant 2)

Most doctors were only able to offer short consultations, but some professionals such as the Clinical Nurse Specialist working in the transplant team, were able to offer more time, which provided opportunities to discuss concerns that patients felt unable to raise with the doctor. Even so, the key purpose of these consultations was also quite focused (to reduce relapse of substance misuse by reducing anxiety in vulnerable patients on the waiting list) and thus patients' broader concerns may still go unanswered.

It's not about answering questions, it's about listening and containing anxiety. It's a big part of the role especially when they come up to me and the doctor has a specific remit and needs $X$ information to make a decision if someone is transplantable. The medical sessions are more directive than mine. People feel less interrogated because I have more time. For a new assessment, we allow an hour compared to 15 minutes the docs have. We have the luxury of being able to do a comprehensive history (Clinical Nurse Specialist - transplant).

Many patients had identified memory issues as a barrier to asking questions. Some specifically referred to episodes of hepatic encephalopathy making it difficult to ask questions. Others simply referred to their condition affecting their memory making it difficult to remember information.

For some patients, there was a perceived stigma associated with cirrhosis that made it difficult for them to ask questions. However, others reported that the continuity afforded by seeing the same clinician with the appropriate clinical expertise at each appointment enabled them to be more comfortable about asking questions.

"I see the [liver] consultant regularly as the liver is the main issue. When you go to the GP to get your results, you never see the same person, because you have to explain your results and yes 'I'm an 
alcoholic.' Likewise, when I get the same doctor, it's much nicer, you don't have to go through [the whole story] and feel as bad." (3104, female, alcohol related liver disease)

Improving the delivery of information

Patients found it difficult to understand the information given by clinicians concerning their disease as it was often couched in technical medical terms.

"The problem for me has always been deciphering the results I am given, because if you don't understand it you can almost turn a blind eye to it, it doesn't seem important because you can't understand how important it is, because you don't know" (3109, male, Alcohol related liver disease).

Patients particularly found the use of statistics unhelpful in describing their disease or its prognosis.

Yes he gives me high level statistics! If you make it through the year, you have a 75\% of making through the next 10 years. So that response is not helpful. I want practical help about what to expect, not just stats and percentages, and how many people live through what time. Obvious caveat being that if I remain abstinent, realistically if I don't drink, how am I going to feel in a year's time? (3103, male, alcohol related liver disease).

Some patients felt that the emphasis on the physical aspect of their care left little time to discuss the psychological impact of their disease, as highlighted by this patient.

"A lot of people with liver disease have got there because of alcohol and that insinuates that there are mental health issues involved. The doctor is very focused on the physical side and not the mental side. My criticism of all liver doctors is they tell you, 'just don't drink' as if it's easy but it's a lot more complicated" (3103, male, alcohol related liver disease).

Instead they preferred explanations about their condition, symptoms and management of their disease to be given in simple language, with particular emphasis on what symptoms to look out for and their significance.

Many patients felt that communication could be improved by providing information sheets, particularly about signs and symptoms of liver disease and potential deterioration as a result of liver disease. One patient found that there was too much information to take in during the clinic, so would have liked to pick up the relevant information sheet about the issues discussed during clinic, to take this information sheet away and digest it in more detail at his own pace.

I like to read about it (the information discussed in the consultation) and pick them (leaflets/booklets) up. You can get to it (access) any time you want (3105, male, non-alcohol fatty liver disease).

Other specific suggestions for improving communication included sending patients copies of their test results, providing a contact point with the clinician for patients to get further explanation or advice about 
their liver disease and getting health professionals to check that patients have understood the information given.

\section{Discussion}

This is the first study to explore the questions asked by patients to hepatology clinicians during outpatient consultations. It highlights the medical focus of these consultations, centred predominantly on the physical aspects of caring for liver disease, but in which questions were also raised about psychosocial support and issues related to supportive care, such as the practical and psychological impact of their disease on their family members. Patients and family members felt comfortable asking questions to clinicians, but ultimately felt that the information they received about prognosis, future treatments and the practical implications of living with deteriorating liver function, could be improved as highlighted in previous studies(2). Some clinicians felt that patients should use their out-patient appointments to address issues related to their future care in the light of deteriorating liver function, or in the case of transplant list patients, their expectations of transplant and their own behaviour posttransplant. This may be because clinicians were not aware that patients did not fully understand their conditions or their prognosis.

We found that the questions asked during out-patient appointments were influenced by whether the patients were on the transplant list or not. Patients on the transplant list asked questions specifically focused on liver transplantation such as their position on the transplant list. It may be that, as this group had more regular visits to the hospital, with a range of multi-disciplinary support (clinical nurse specialists, a dietician and a psychologist), most of their needs were being catered for.

This study provides some insight as to why patients and liver health professionals feel uneasy about discussing psychosocial and existential issues. As with previous studies $(2,4)$, the lack of time within the medical consultation was identified as a barrier to potentially asking questions. Our findings suggest that clinicians are reluctant to discuss existential issues as they feel that these cannot be sensitively and adequately addressed in a 15 minute consultation. Other studies have suggested that clinicians feel that they do not have sufficient skills to discuss such existential issues(4). As with previous studies(5), the stigma that some patients with cirrhosis felt about their liver disease could act as a barrier to communication.

\section{Study limitations}

This is a secondary analysis of data from a study, the primary aim of which was, to identify items for inclusion in a Question Prompt List(13). The focus of this analysis has been to explore what questions were asked between patients and clinicians during their out-patient appointments and what difficulties the different participants had in asking and answering questions. The methodology used was pragmatic, to reflect the aims of the original study, and to be sufficient to obtain a descriptive account about the nature of out-patient consultations. However, unlike in other studies looking at clinical conversations(16), our interviews did not allow a deeper exploration about the nature of the conversations that patients had 
with health professionals. Our sample size was limited to 12 patients, six family member and 14 health professionals. This was considered adequate for the purposes of the original study, but may not have achieved data saturation of the themes related to patient-health professional communication. Due to practical and resource constraints, the contents of each interview were not transcribed in their entirety, so some key themes may have been missed. In analysing participants' responses to the questions, we assumed that participants gave honest responses on the topics discussed.

\section{Implications for practice and future research}

Health professionals should aim to use simple language when providing patients and their families with explanations about liver disease, its impact and prognosis. Information sheets about these topics should be prepared and made available for patients to take home. Doctors should be willing to explore supportive care issues with patients and, if there is insufficient time for these issues to be adequately addressed in the medical appointment, then they should consider referring the patient to another member of the multi-disciplinary team who may potentially have more time and expertise to discuss such issues at length. Different ways to initiate conversations about difficult topics such as the Question Prompt List that we have described elsewhere(13) may also act as a communication aid. Future studies are needed providing insights into how healthcare professionals and patients communicate with each other(17). These could specifically explore the nature of out-patient consultations, using naturalistic methods such as participant observation or conversation analysis as a way of unpicking the complex nature of these clinician patient interactions.

\section{Conclusion}

This is the first study to report the specific contents of the conversations between clinicians and patients during liver out-patient clinics. Further work is needed to explore the interactions between these groups using observational methods.

\section{Box 1: Eligibility Criteria}

Patients:

- at least one episode of decompensation

- identified as having a diagnosis of cirrhosis by the clinician

- a sufficient level of spoken English to discuss relevant issues

- aged $\geq 18$ years

- not cognitively impaired

Close family member 
- attending outpatient clinics with their associated patient

- identified either by patients or health professionals as the main provider of individual physical and emotional care, and not employed by statutory or voluntary services to provide this care

- Sufficient level of spoken English to discuss relevant issues

- Aged $\geq 18$ years

Medical and nursing health professionals

- Any professional providing direct care and consultation to patients with liver cirrhosis in out-patient clinics.

\section{Box 2: Topic Guide For Patient And Close Family Members (Adapted From Mcjarrett Et Al 2002)}

- When you see your doctor what are the questions that you asked during the consultation?

- Are there any questions what you wanted to ask but felt uncomfortable to do so?

- How easy do you find it to ask questions? What would make it easier to ask these questions?

- Do you do anything to prepare for consultations?

- How easy it is to retain the information you receive?

- Are there topics you would like to cover that are currently not covered?

\section{Tables}

Table 1: Demographic details of participants 


\begin{tabular}{|c|c|c|}
\hline \multicolumn{3}{|l|}{ Characteristic } \\
\hline \multicolumn{3}{|l|}{ Patient $(\mathrm{N}=12)$} \\
\hline \multirow[t]{2}{*}{ Age (years) } & mean (sd) & $51(11)$ \\
\hline & $\min -\max$ & $31-69$ \\
\hline \multirow[t]{2}{*}{ Gender (\%) } & Male & $8(67)$ \\
\hline & Female & $4(33)$ \\
\hline \multirow[t]{4}{*}{ Ethnicity (\%) } & White British & $7(58)$ \\
\hline & White European & $3(25)$ \\
\hline & South Asian & $1(7.5)$ \\
\hline & Other & $1(7.5)$ \\
\hline \multirow[t]{5}{*}{ Cause of cirrhosis (\%) } & Alcohol related liver disease & $\begin{array}{l}6(50) \\
3(17)\end{array}$ \\
\hline & NASH/NAFLD & $3(17)$ \\
\hline & Hepatitis C & $1(3)$ \\
\hline & Idiopathic & \\
\hline & Unknown & \\
\hline \multicolumn{3}{|l|}{ Close family member $(\mathrm{N}=6)$} \\
\hline \multirow[t]{3}{*}{ Relationship status } & Parent & 3 \\
\hline & Son & 2 \\
\hline & Spouse & 1 \\
\hline \multirow[t]{2}{*}{ Gender (\%) } & Male & $3(50)$ \\
\hline & Female & $3(50)$ \\
\hline Ethnicity (\%) & White British & $6(100)$ \\
\hline \multirow[t]{3}{*}{ Cause of patient cirrhosis (\%) } & Alcohol related liver disease & $3(50)$ \\
\hline & NASH & $1(17)$ \\
\hline & Unknown & 2 (33) \\
\hline \multicolumn{3}{|l|}{ Health professional $(\mathrm{N}=14)$} \\
\hline \multirow[t]{6}{*}{ Profession (\%) } & Consultant hepatologist & $5(36)$ \\
\hline & Registrar/Clinical fellow & $2(14)$ \\
\hline & Transplant nurse co-ordinators & $4(29)$ \\
\hline & Clinical Nurse Specialist & $1(7)$ \\
\hline & Alcohol liaison nurse & $1(7)$ \\
\hline & Dietician & $1(7)$ \\
\hline
\end{tabular}

Table 2: Questions asked or not asked during hepatology out-patient consultations - Frequency of responses from participants 


\begin{tabular}{|c|c|c|c|c|}
\hline & $\begin{array}{l}\text { Patient } \\
(n=12)\end{array}$ & $\begin{array}{l}\text { Family member } \\
(n=6)\end{array}$ & $\underset{(n=13)}{\mathrm{HP}}$ & Total \\
\hline Questions asked during consultation & & & & \\
\hline Discussion of test results & 7 & & & 7 \\
\hline $\begin{array}{l}\text { Discussion of symptoms and/or their } \\
\text { management }\end{array}$ & 4 & & 3 & 7 \\
\hline Treatments available & 3 & & 3 & 6 \\
\hline Improving liver function/general health & 4 & & 1 & 5 \\
\hline Medication & 2 & & 3 & 5 \\
\hline $\begin{array}{l}\text { Information on their own disease } \\
\text { disease/proaression }\end{array}$ & 3 & & 2 & 5 \\
\hline Psychological/counselling & 2 & & 1 & 3 \\
\hline Will I die & & & 2 & 2 \\
\hline More information on diet for liver disease & 2 & & 2 & 2 \\
\hline Management of patient at home & & 1 & & 1 \\
\hline $\begin{array}{l}\text { Impact of disease on disease on family } \\
\text { members }\end{array}$ & & & 1 & 1 \\
\hline Why am I not on the transplant list & 1 & & & 1 \\
\hline Important questions not asked & & & & \\
\hline Symptoms to look out for & 1 & 1 & 2 & 4 \\
\hline Diet & 1 & 1 & 2 & 4 \\
\hline Better information about prognosis & 3 & & & 3 \\
\hline What happens if liver disease gets worse & 1 & & 1 & 2 \\
\hline Possible treatments & 1 & 1 & & 2 \\
\hline Physical conditions & 1 & & 1 & 2 \\
\hline Future & & 1 & 1 & 2 \\
\hline Future plans, setting up will & & & 1 & 1 \\
\hline Impact of medication on symptoms & & & 1 & 1 \\
\hline Ability to discuss feelings & 1 & & & 1 \\
\hline Payment for travel, practical issues & & & 1 & 1 \\
\hline Complications post-transplant & & & 1 & 1 \\
\hline Post-transplant behaviour & & & 1 & 1 \\
\hline Transplant-specific questions asked & & & & \\
\hline Position on the transplant list & 1 & & 5 & 6 \\
\hline Diet & 1 & & 2 & 3 \\
\hline Financial support & & & 2 & 2 \\
\hline Expectations of being on transplant & & & 1 & 1 \\
\hline Social support & & & 1 & 1 \\
\hline Driving & & & 1 & 1 \\
\hline Donor backup & & & 1 & 1 \\
\hline What will happen & & & 1 & 1 \\
\hline $\begin{array}{l}\text { Practicalities and anxieties of waiting for } \\
\text { transplant }\end{array}$ & & & 1 & 1 \\
\hline
\end{tabular}

\section{References}

1.Health NIf, Excellence C. Patient experience in adult NHS services: improving the experience of care for people using adult NHS services: National Institute for Health and Clinical Excellence; 2012. 
2.Kimbell B, Boyd K, Kendall M, Iredale J, Murray SA. Managing uncertainty in advanced liver disease: a qualitative, multiperspective, serial interview study. BMJ open. 2015;5(11):e009241.

3.Low JT, Rohde G, Pittordou K, Candy B, Davis S, Marshall A, et al. Supportive and palliative care in people with cirrhosis: International systematic review of the perspective of patients, family members and health professionals. 2018;69(6):1260-73.

4. Hudson B, Hunt V, Waylen A, McCune CA, Verne J, Forbes K. The incompatibility of healthcare services and end-of-life needs in advanced liver disease: A qualitative interview study of patients and bereaved carers. Palliative medicine. 2018;32(5):908-18.

5.Künzler-Heule P, Beckmann S, Mahrer-Imhof R, Semela D, Händler-Schuster D. Being an informal caregiver for a relative with liver cirrhosis and overt hepatic encephalopathy: a phenomenological study. Journal of clinical nursing. 2016;25(17-18):2559-68.

6.Fagerström C, Frisman GH. Living With Liver Cirrhosis: A Vulnerable Life. Gastroenterology Nursing. 2017;40(1):38-46.

7.Day R, Hollywood C, Durrant D, Perkins P. Patient experience of non-malignant ascites and its treatment: a qualitative study. International journal of palliative nursing. 2015;21(8):372-9.

8.Grønkjær LL, Andersen NG, Hansen LB, Sehstedt TH, Svensson NT, Sømod IE, et al. Different views on hepatic encephalopathy: patients, relatives and nurses. Gastrointestinal Nursing. 2016;14(Sup10):S24S31.

9.Vaughn-Sandler V, Sherman C, Aronsohn A, Volk ML. Consequences of perceived stigma among patients with cirrhosis. Digestive diseases and sciences. 2014;59(3):681-6.

10.Mikkelsen MR, Hendriksen C, Schiødt FV, Rydahl-Hansen S. Coping and rehabilitation in alcoholic liver disease patients after hepatic encephalopathy-in interaction with professionals and relatives. Journal of clinical nursing. 2015;24(23-24):3627-37.

11.Low J, Vickerstaff V, Davis S, Bichard J, Greenslade L, Hopkins K, et al. Palliative care for cirrhosis: a UK survey of health professionals' perceptions, current practice and future needs. Frontline Gastroenterology. 2015:flgastro-2015-100613.

12. Heritage $J$. The interaction order and clinical practice: Some observations on dysfunctions and action steps. Patient education and counseling. 2011;84(3):338-43.

13.Low JD, S; Vickerstaff, V; Gola, A; Marshall, A; Rohde, G; Greenslade, L; Thorburn, D; Craig, R; Wilson, J; Stone, P. Improving Communication in Medical Consultations for People with Advanced Liver Disease: The Development of a Question Prompt List (QPL). Palliative Medicine. 2018;32(1_suppl):101. 
14.McJannett M, Butow P, Tattersall MHN, Thompson JF. Asking questions can help: development of a question prompt list for cancer patients seeing a surgeon. European journal of cancer prevention: the official journal of the European Cancer Prevention Organisation (ECP). 2003;12(5):397-405.

15.Ritchie J, Spencer L, O'Connor W. Carrying out qualitative analysis. Qualitative research practice: A guide for social science students and researchers. 2003:219-62.

16.Clover A, Browne J, McErlain P, Vandenberg B. Patient approaches to clinical conversations in the palliative care setting. Journal of Advanced Nursing. 2004;48(4):333-41.

17.Parry R, Land V, Seymour J. How to communicate with patients about future illness progression and end of life: a systematic review. BMJ supportive \& palliative care. 2014;4(4):331-41. 